\title{
STANDARDISING THE INFORMATION TECHNOLOGY ENVIRONMENT AT TELSTRA CORPORATION: A CASE STUDY
}

\author{
Carey Butler and Peter Weill \\ Key Centre for Technology Management, Melbourne Business School, \\ University of Melbourne \\ Email: c.butler@mbs.unimelb.edu.au and p.weill@mbs.unimelb.edu.au
}

\begin{abstract}
Telstra is Australia's leading telecommunications carrier and largest single user of information technology (IT). In November 1990, the Australian federal government announced wide-ranging reforms and the introduction of competition within the telecommunications sector. Realising that it was essential for the corporation to leverage its use of technology on a firm-wide basis in order to remain a strong and flexible competitor, in 1991, Telstra embarked upon a major overhaul of its existing IT infrastructure. Central to this was the establishment of standardised operating environments (SOE) for all computing resources used at Telstra.

This paper traces the development of Telstra's data network and desktop SOEs. The paper examines the strategic drivers for the SOEs, the business benefits, and issues related to Telstra's computing environment prior to, and after the introduction of network and desktop SOEs.
\end{abstract}

\section{INTRODUCTION}

"Our industry is in transition. Rapidly developing new technologies, new markets, fierce competition and higher customer expectations are combining to generate change on a scale never experienced in the Australian telecommunications industry"

- Frank Blount, CEO, Telstra Annual Report 1994.

In late 1994, Brian Lovelock, Telstra's CIO, sat in his office at Telstra's corporate headquarters in Melbourne, Australia and contemplated the future. Over the last three years the Australian telecommunications marketplace had changed remarkably since the introduction of a competitor to Telstra's traditionally monopolistic domain. Significant change had also occurred within Telstra itself, as it rose to the challenge of competition by improving customer responsiveness, and striving for service excellence.

Since 1991, Telstra had also undertaken a major overhaul and rationalisation of its internal communications environment. This change had standardised the company's voice and data platforms, and greatly improved access to information resources across the firm. More change was necessary Lovelock realised, as his eyes scanned the Melbourne cityscape far below. Full unrestricted competition in the telecommunications sector was planned for 1997. Lovelock wondered what this would mean for Telstra, and whether the information technology initiatives implemented so far would be sufficient to support future business needs as the marketplace underwent yet another major transformation.

\section{BACKGROUND}

\section{Telecommunications Environment in Australia}

For many years, the provision of telecommunications services in Australia was the sole domain of three government-owned instrumentalities - the domestic carrier ${ }^{9}$ Telecom, the international carrier OTC $^{10}$, and the national satellite carrier AUSSAT. In 1987, the Commonwealth Government of Australia undertook a fundamental review of the Australian telecommunications industry. In November 1990, this resulted in the announcement of wide-ranging reforms to the basic structural and regulatory framework of the telecommunications sector. Reforms focused on the introduction of broad-based competition and a restructuring of the three monopoly carriers. In 1991/92, this resulted in the establishment of a competitive duopoly, based on a single government-owned carrier (AOTC) ${ }^{11}$ and a private sector carrier (Optus Communications) ${ }^{12}$. Both telcos offer domestic and international services, with Optus currently holding around 10\% marketshare.

\footnotetext{
9 international carriers Telecom and OTC.
}

The formation of a second carrier was conditional upon the privatisation of AUSSAT. 
Cessation of the duopoly is planned for July 1, 1997 when the Australian telecommunications marketplace will be opened up to full, unrestricted competition.

Telecommunications is one of the most rapidly expanding industry sectors in Australia. The last decade has seen the introduction of consumer choice in terms of a wide range of different products, equipment and services. Strong growth has occurred in long distance and international telephone call rates. Cellular mobile calls have grown at an astounding rate increasing from 3 million in 1987, to 319 million in 1992 (S\&P 1993a), with one in every fifteen Australians now owning a mobile phone.

\section{The Formation of Telstra Corporation}

In 1991, Telecom and OTC merged their operations to become AOTC ${ }^{13}$. In 1993, the name AOTC was replaced by Telstra Corporation. The company provides a full range of telecommunication services and products to domestic and international customers. Although government-owned, Telstra operates as a separate commercial enterprise, employing some 60,000 staff.

Telstra is headquartered in Melbourne, and owns around 10,000 sites $^{14}$ throughout Australia. It also has business offices or joint ventures in 20 countries around the world. The high growth Asia/Pacific region is a particular area of current interest and investment.

Internationally, Telstra owns around $2 \%$ of telephone lines worldwide, is the third largest owner of submarine cables in the world, and has one of the largest digitised terrestrial networks in the world with over $1,000,000 \mathrm{~km}$ of fibre optic cable in active service. Within Australia, Telstra currently handles around 10 million telephone calls per day. The company's customer base is the largest of any Australian enterprise, with more than $95.5 \%$ of Australian households connected to its domestic telephone network.

\section{Organisational Structure:}

The merger of Telecom and OTC prompted the need for wide-ranging realignment and restructuring within the new company in order to eliminate duplication of functions and other inefficiencies. "The changes we have made deal with the very structure of our organisation and with all of our systems: management, financial, operating and product/service development", said Telstra's Chief Executive Officer (CEO), Frank Blount (AOTC 1992a).

Change was driven by the broad-based needs of the new competitive market and by specific customer needs. The Corporation reorganised itself into a number of semi-autonomous business divisions ${ }^{15}$ (see Figure 1 ), and a Corporate Centre function. Each division has its own customers, its own assets, its own team of employees, and its own culture within the context of the overall organisational culture. The Corporate Centre provides support to the various business divisions, and is responsible for planning and decision-making related to the long term strategic direction of the firm.

In 1994, there were six major businesses, each with commercial accountability and a central focus on servicing the needs of a particular customer group. "For example, corporate consumers are handled separately to residential consumers", said Michael Bennett, former National Manager for Telstra Desktop Solutions. "We are aware that our customers have a choice in service providers, and that we have to do all we can to win those customers each and every day."

At the same time the divisions were established, Shared Resource Units (SRUs) for activities such as accounting, supply, property management and a corporate level Information Technology Group (ITG) were also set up to provide services across the customer divisions. "The SRUs transfer price their costs to the divisions and are required to be competitive with service supply external to Telstra", said Bennett. The sheer size and scope of Telstra's operations, means that single Business Units are often dispersed over multiple geographic locations. Commercial and Consumer (see Figure l) is a case in point; with over 32,000 staff, it is the firm's largest business unit.

The Corporation has established an organisation characterised by individual, multi-disciplined teams of people, focused on unique markets. This arrangement enables the various businesses to quickly respond to the changing needs and demands of customers, while still working within an 'envelope' of Corporate-wide expertise. 


\section{Figure 1: Business Divisions at Telstra}

\begin{tabular}{|l|l|}
\hline $\begin{array}{l}\text { Finance and } \\
\text { Administration }\end{array}$ & $\begin{array}{l}\text { is part of the Corporate Centre, and has responsibility for } \\
\text { corporate and strategic functions such as corporate finance, } \\
\text { treasury, audit, business planning and regulatory affairs, } \\
\text { corporate affairs, and legal matters. }\end{array}$ \\
\hline $\begin{array}{l}\text { Corporate, } \\
\text { and } \\
\text { Enterprises }\end{array}$ & $\begin{array}{l}\text { Corporate provides services to around 3,000 of Australia's } \\
\text { largest enterprises from the corporate and government sectors. } \\
\text { Services include: customised voice and data transfer, value- } \\
\text { added services, facilities management and systems integration. } \\
\text { International is structured around the core of the former OTC. } \\
\text { This unit provides overseas telecommunication services and } \\
\text { products. Customers are typically Australian organisations } \\
\text { with significant offshore operations, and foreign multinationals } \\
\text { Enterprises operates two lines of business - mobile } \\
\text { communications services, and directory products and services. } \\
\text { Each line is responsible for its own operating profit, controls its } \\
\text { own assets, and manages its own product development, sales } \\
\text { and marketing teams. }\end{array}$ \\
\hline Commercial \& Consumer & $\begin{array}{l}\text { Commercial provides products and services to 840,000 small } \\
\text { and medium-sized Australian businesses. This represents more } \\
\text { than 80\% of telephone services. } \\
\text { Consumer delivers telecommunication and information services } \\
\text { to around } 6 \text { million residential customers. }\end{array}$ \\
\hline Network and Technology & $\begin{array}{l}\text { owns Telstra's core network, and oversees network planning, } \\
\text { development, construction and operations. The unit is also } \\
\text { responsible for developing network products, and for the } \\
\text { wholesale marketing of these to Telstra's own retailing business } \\
\text { units and to other carriers. }\end{array}$ \\
\hline
\end{tabular}

\section{Business Strategy:}

The merger of Telecom in 1991 with the smaller, but highly profitable OTC, resulted in an organisation with a strong presence ${ }^{16}$ across all market segments. The new corporation has sought to protect its revenue and marketshare by:

- $\quad$ introducing new products and services which focus on customer needs;

- $\quad$ aggressively marketing its services;

- improving the range and quality of its services through network modernisation. In 1994, Telstra announced a A $\$ 3.3 \mathrm{~b}$ network modernisation program for its Australian network;

- $\quad$ introducing new operational systems; and

- $\quad$ re-orienting itself to customer focused performance targets (S\&P 1993b).

These initiatives have been effective in retarding revenue loss as competition increases in the marketplace, and are clearly reflected in Telstra's Corporate Plan which has a strong customer focus, and is geared towards "the aggressive pursuit of business success within both the newly competitive Australian market and offshore." (AOTC 1992a). Key Business Imperatives include:

- $\quad$ achieving excellence in customer service and value;

- $\quad$ striving for world's best practice financial performance, including competitive pricing and management of costs, capital efficiency and systems support; and

- driving business growth, through the development of new markets in Australia and offshore. 
Despite competition and the inevitable erosion of some market share, Telstra is in a sound position. To date, it has increased profit and revenue, expanded its markets - both domestically and offshore - improved customer service, and contained spending in most areas. The Corporation has clear goals for the future which include making it the first choice among customers with telecommunications needs, becoming a leading player in the Asia-Pacific region, and ultimately, one of the most effective, most efficient and most innovative telecommunications companies in the world.

\section{TELSTRA IT ENVIRONMENT (1994)}

Telstra is Australia's largest single user of information technology (IT), with an annual expenditure in this area of many millions of dollars. More than half of the 60,000 staff employed by Telstra use IT applications as part of their every day work. Many of these applications are Telstra specific, mainframe-based systems, but other user applications such as wordprocessing, spreadsheets and email are microcomputer-based. Telstra is the largest Microsoft Mail site in the world.

\section{Conceptual Framework for IT:}

A conceptual framework for the development and delivery of all major information systems for Telstra operations is provided by the firm's Overall Systems Architecture (OSA). OSA is in turn based on a number of business drivers which are a direct extension of the firm's Key Business Imperatives. OSA provides the architecture to integrate Telstra's business processes, its systems and its network. OSA specifies a number of discrete processing layers ${ }^{17}$, and focuses attention on system "building blocks" - groupings of business functionality and data. OSA imperatives include ensuring:

- provision of the highest quality customer services;

- provision of timely, accurate and relevant management information so that business managers can better direct, manage and control the business;

- development of business systems that meet Telstra's current and future business needs;

- alignment of systems with business processes;

- core applications are adequately integrated, and major hardware platforms are compatible;

- IT maximum value for money is obtained from expenditure on IT;

- capabilities are fully exploited to assist the introduction of new business activities and new work practices; and

- $\quad$ reduction of costs through more efficient and effective use of network resources.

A summary of OSA's key principles, major drivers, and its linkages with Telstra's main business functions and processes is shown in Figure 2.

\section{Current IT Platform:}

In Australia, Telstra has two major data centres accommodating a wide variety of hardware, and a network size of 1,500 locations supporting around 46,000 terminals. $87 \%$ of these terminals are personal computers (ABM 1994). Telstra's current hardware platform includes eight Amdahl mainframes, two IBM ES/9000 mainframes, seven Bull mainframes, and a number of HP, Pyramid and Sun midrange processors.

Systems running on the Bull mainframes are gradually being migrated over to the IBM machines. Telstra uses Unix and a number of proprietary operating systems. Database management systems include DB2, Adabas and Oracle. SAP's mainframe-based $R / 2$ is currently being implemented to manage back office operations. Core application areas include: Billing, Customer Management, Service Delivery, Trouble Management, Product Management and Network Plant Assignment.

Telstra has a history of developing its IT solutions inhouse. "For large scale developments that approach is still true", said John Mitchell, Telstra's Manager for Network Rationalisation. "We have a strong ethos of inhouse support and development, partly because of the control that this approach confers, but mainly because many of our big systems are very specific to Telstra."

17 Which are aligned to established or emerging international communications standards 


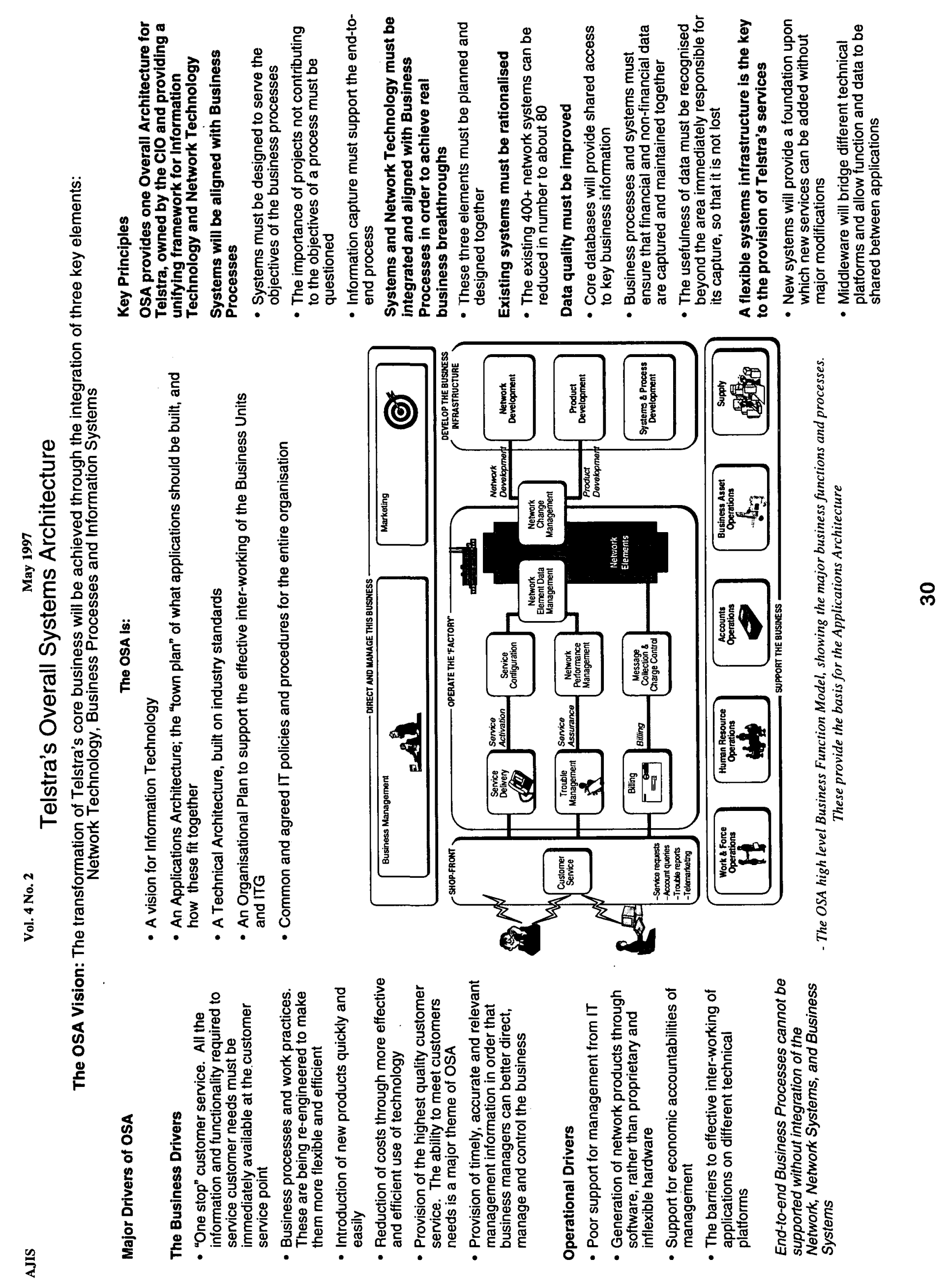




\section{THE NEED FOR A STANDARD OPERATING ENVIRONMENT (SOE)}

\section{Host Systems Connectivity:}

Telstra's use of IT is longstanding, and during the 1970s and 1980s was based around large, independent mainframe systems using single dumb terminal workstations to service one application. "As we progressed through the 1980s", said Mitchell "it became increasingly apparent that this approach was insufficient for business needs. The number of applications grew, mainframe usage grew dramatically, and there was a need for terminals to be multifunctional. Because of system incompatibilities, a situation developed where some people had three workstations on their desks. Each of these was used for a different application or for accessing a different system. Clearly this was not sensible, scalable or sustainable."

Bob James, Telstra's Group General Manager for Strategic Development agreed: "When people had three terminals on their desks, it was easy to visualise five or even ten. We realised we needed single terminal access, but dumb terminals that could handle multiple protocols didn't exist. Around 1987/88, LANs started to become commercially viable, minicomputers appeared, and PCS were becoming serious business support tools."

In 1988, Telstra partially solved the problem of host connectivity by moving to a PC LAN (refer Figure 3) environment, and developing Drift. Drift is an inhouse protocol emulation software toolkit that transparently links to several different mainframes irrespective of platform, thereby enabling corporate data to be accessed from the desktop. Drift allows a single PC to do the job of up to nine dumb terminals, and has saved Telstra the considerable expense of rewriting many of its mainframe applications. "All this was done under DISNet ", said Bennett, "an early network that really pushed the move to LANs. Another driver was that PCs with emulation cards were now actually cheaper than dumb terminals. Drift resided on a PC connected to a LAN file server, which connected to a communications server, which in turn connected to Austpac. ${ }^{19}$ Any user connected to the file server could get access to host system applications."

\section{Workgroup Connectivity:}

For many years Telstra had taken a decentralised approach towards IT, in allowing its various businesses to conceive and implement IT solutions tailored to their individual needs. While this method was generally effective at a local level, corporate-wide pooling and interchange of information, was difficult, time consuming and frequently impossible. Telstra has thousands of buildings, so workgroups are often spread over a number of geographic sites. By the late 1980s, Telstra's technology base had evolved into a complex series of numerous, largely isolated networks based on many different vendor offerings.

Electronic mail could be sent within individual businesses but not necessarily firmwide because of platform and/or email software differences. Network management was also an issue. "On one of the larger networks, there were problems like "broadcast storms", where traffic would just avalanche through the network and bring it to crash point", said James.

Cost and duplication of effort were other issues. "Many of the networks almost paralleled each other", said James. "The Corporate Customer Division had individual Melbourne to Sydney links, so did Business Services and so did the Residential Division, and yet they were all part of the same company. The cost of communications to Telstra was immense, particularly when you consider that any one group in the company is as large as the Australian Federal Government in terms of spend. There was a lot of inconsistency and incompatibility. Telstra's purchasing leverage was not being maximised."

Responsibility for IT decisions in terms of systems development, equipment and software choice was largely localised. "What we ended up with", recalled James, "was a situation where every organisation within Telstra had different data networks and voice facilities, had its own IT group. and its own ideas about which PC environment (DOS or Macintosh), email package or office applications should be purchased." For staff moving to jobs in different areas of Telstra, this often entailed a substantial learning curve with every new job move. "Another problem", commented Brian Lovelock, "is that organisational entities within Telstra tend to have a half-life of about 18 months. So if part of Business Services had moved into the Corporate Customer Division they would have had to change their network!"

By the late 1980s, Telstra was operating twenty six large and separate networks, with little ability to intercommunicate. "That's when things came to a head for us", recalled James "and we realised the need for a solution not only at the network level, but down to the desktop as well." But it was the business drivers that were really the key motivators. 
"Telstra's move in the late 1980s to a business driven, customer focus", said Bennett "underlined an urgent need to move away from the isolated systems of the pre-competitive era, towards developing integrated information systems that could be used across the organisation. Our CEO had identified a number of Key Business Imperatives. These were used as the basis for development of our Overall Systems Architecture principles which further expanded them in the areas where IT played a decisive role. You only have to glance at these to realise that the focus is on satisfying the customer and on more efficient use of our internal communications networks."

Maximising the effect on customer focus will be a lot easier with a communications environment that exhibits synergy between systems, and an ongoing flexibility to grow apace with changing company and customer needs. We are aiming for a level of integration where all the information and the functionality required to service any customer need is immediately available from the one service point - the "one-stop" shop approach. And this is regardless of where the information is stored or on which system. A return to how we were in the late 1980s is now unthinkable."

\section{DEVELOPMENT OF A STANDARD OPERATING ENVIRONMENT}

In 1990, a corporate-level Information Technology Group (ITG) was formed with a specific mandate to devise and implement a technology framework for integrating Telstra's internal communication systems, reducing associated costs, and improving customer access across the firm. "This was a first for Telstra", said Bennett. "Prior to this, no such group had ever existed." ITG has responsibility for IT Policies and Architectures, Strategic Planning, Management of Core Projects and Provision of IT services. The businesses are responsible for Tactical Planning, Expenditure, Definition of Requirements and Management of Non-Core Projects. "ITG has been entrusted with forming the needed balance between building a centralised IT infrastructure and working with the BUs to develop the systems they require", said Bennett.

A key initiative for achieving these objectives was the development of a consistent environment for voice and data networks that would bridge current technology islands, and provide a fast, flexible, reliable platform that was independent of geographical or organisational boundaries. Bob James was working as General Manager of ITG Networks at this time: "In 1991, we came up with the idea of a standard operating environment (SOE) which was a concept we borrowed from $A T \& T^{20}$ who used it for software specification. We took it much further in applying it to hardware as well, and by producing a product guide." The product guide ${ }^{21}$ specified which software, hardware, networking and telecommunications products were to be used within Telstra right down to the particular model number of a printer or version number of operating system software. Documents which broadly defined the SOE for the desktop, data networks and voice networks were also developed at this time.

Telstra SOEs specify the general technical environment for a broad base of users across all areas of the organisation. SOEs are the actionable aspects of Telstra's Overall Systems Architecture. The SOEs also address the more specific development and operating environments which are required by specialised areas such as development teams and network specialists. SOE content is dynamic, and changes according to business needs and/or ongoing technological advancements. SOE categories include:

Desktop specifies the parameters for all desktop-related hardware and software

Network applies to the purchasing and installation of all LAN and WAN network products, and to development of applications in the corporate network environment

Processing addresses the operational environment for core applications that support the main business functions within Telstra

20 AT\&T is a major American telco.

21 There are currently 24 hardware and software suppliers listed in the product guide, arranged in 4 categories: desktop, networking, enterprise and mid-range solutions (MIS (Australia), Winter 1994. p. 100). 


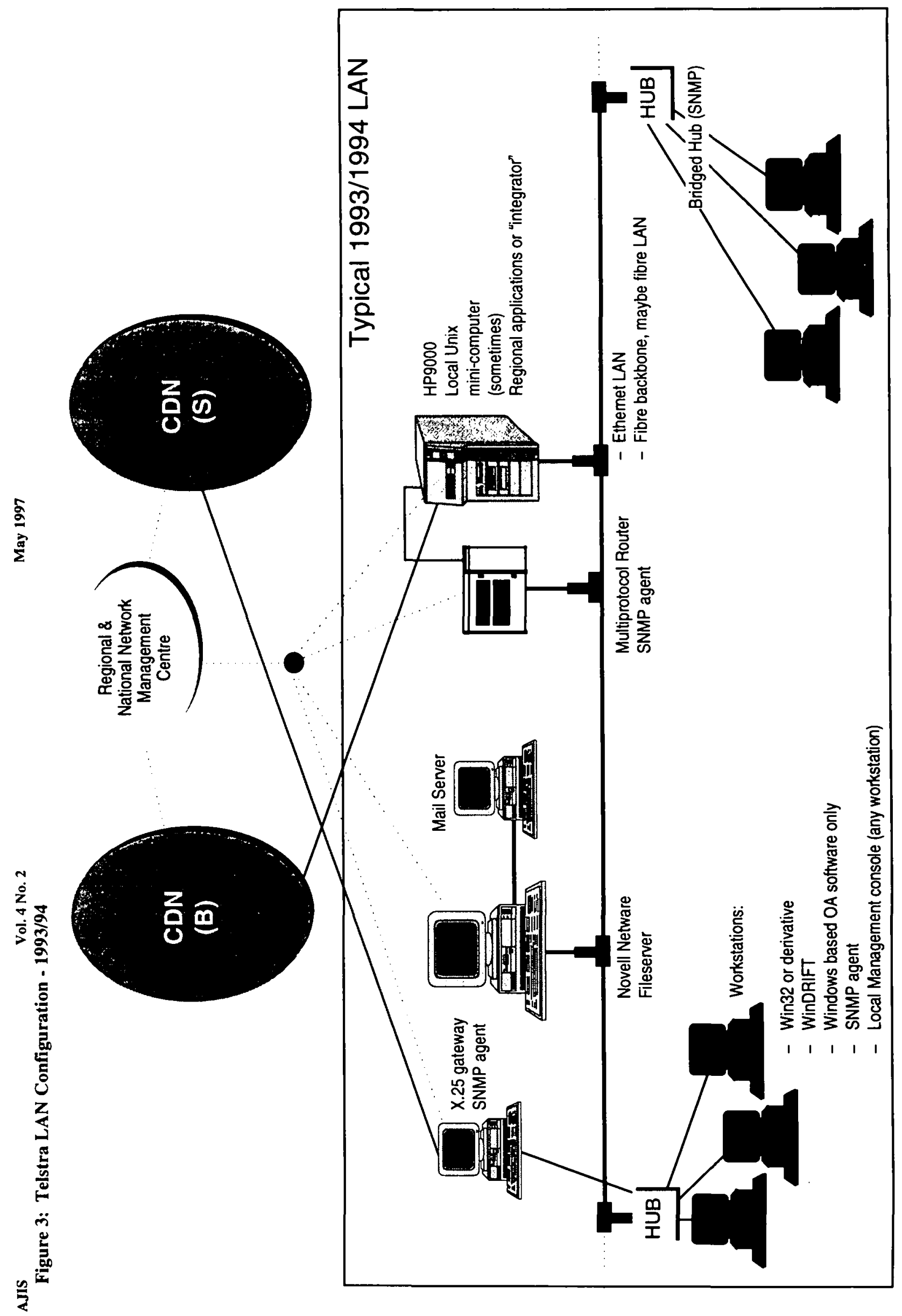


"We had a family of concepts and supporting documents", said James "and each of these was a separate standardisation exercise. Having set the path for change, the next task was convincing people that they needed to move to SOE. We chose the desktop as the first target for introduction of SOE; it was people-intensive, and it was also an area where we reckoned the businesses could make significant savings in the purchase of hardware and software. We hoped this would provide sufficient incentive to adopt the SOE."

\section{Desktop SOE:}

Standardisation of the desktop started in 1990. "By mid-1990, it became obvious that PCs and the Windows environment had come of age", said Bennett. "At the time Telstra had around 20,000 PCs and 2,000 Macintoshs, which is roughly the user ratio worldwide. Mac users were ferociously loyal, but PCs were already connecting to mainframes systems via Drift ${ }^{22}$, and there were connectivity difficulties with the Mac. As integration of applications was the central gameplan, choosing a microcomputer ${ }^{23}$ standard was really relatively simple."

"We established centralised contracts with absolutely world beating prices for desktop products", said James. "We used to buy hardware and software on a per PC or per software package basis. During the late 1980s, we changed that buying model completely by going out to tender for 10,000 PCs at a time. The net result was that we ended up getting AT machines for the price of an XT. For the desktop SOE, we further improved the buying model by setting up approximate quantity contracts. This meant the business units could deal directly with the end vendor and still get the contract price. We also managed to reduce the supply time down from many weeks to several days. We currently have three vendors who compete for supply of our hardware." These arrangements provided a big incentive for the businesses to move to SOE-compliant hardware products.

"The SOE specifies minimum standards and the most economic approach for the purchasing of new equipment", said Bennett "and in 1994/95, "486 machines were the standard. However back in 1991. the original SOE for desktop machines was for '386s, and the majority of Telstra's machines are still '386s. These are upgraded to "486 level on a business needs basis."

Telstra also used the leverage of its buying power when it came to purchasing software for the desktop.

"In 1991, we did the world's largest deal for Windows products", recalled James. "The initial Microsoft agreement was a multi-million dollar contract, which covered the operating system, word processing, spreadsheet, graphics and project management application packages."

In 1992/1993, Telstra established a corporate level agreement with Microsoft for the supply of software. "At the time, you could only buy software a box at a time", said James. "and a quantity contract usually just meant a discount per box." The new agreement with Microsoft moved away from box licences to user licences, and then progressed to blanket fee corporate licences. This enabled Telstra to greatly reduce the annual cost of software from several thousand dollars per user to several hundred. Further cost and time reductions have been made by confining application installations to Telstra's 1,300 LAN file servers rather than individual machines. "It means we only need one copy of each application on the file server," said Bennett who became National Manager for Telstra Desktop Solutions in 1992. "Manageability is a big issue; it's a lot more efficient to upgrade applications at the file server level than locally upgrading over 40,000 hard disks."

Under Telstra's software arrangements, SOE-compliant products are effectively free to users. This has provided many of the businesses with a big incentive to adopt the new standards. "We could never force people to use the Microsoft products", said Bennett "but when the choice was spending $\$ 600$ for a single copy of Wordperfect and facing a lot of interworking problems, or seamless integration with Word for Windows that was ostensibly free, there was really no contest."

Databases have not been included in the desktop SOE specification as Telstra does not believe PCs are an appropriate place to store corporate-level data of this nature. "Core database systems such as Oracle and DB2 run on the mainframes and provide shared access to key business information", said Bennett. "All PCs have mainframe access. If people want to compile local databases they can use Excel as a flat file to do this."

Electronic mail is another component of Telstra's desktop SOE, and was one of the key drivers. The establishment of corporate-wide email would enable staff to send and exchange messages, documents and files at an inter-business level, and encourage greater communication within the organisation. "Up until the early 1990s, there was no corporate email at Telstra", said Bennett. "We had 9,000 email users on 12 different systems. These were a legacy from the days when individual business groups 
made their own decisions on IT needs. We developed a service called Officelink which used the mainframe-based SofiSwitch product to integrate all the disparate mail systems then in use. We were able to use this as a migration tool for moving towards a single email system based on Microsoft's MS Mail." Migration to the new mail system started in June 1991. By June 1994, Telstra was the largest Microsoft mail site in the world with 37,500 users across Australia, and end-to-end delivery anywhere on its corporate network within 10 minutes.

Bennett believes implementation of the desktop SOE has been much more rapid than originally planned. "We thought it would take four years to conver our disparate users to the SOE standards, but three years later the vast majority of our users are now following the standards. While the corporate licence with Microsoft has undoubtedly provided some of the impetus for this, the main reason seems to be that people are realising the benefits of standardisation and integration much earlier than we expected. Implementation of our corporate email system also greatly assisted in communicating the benefits to be had from a desktop SOE."

Provision of a common infrastructure for the desktop has greatly reduced previous software and hardware incompatibilities and all associated costs, simplified purchasing arrangements, cut training and servicing costs, and markedly improved communications across the firm. "It's completely changed the way we work", said Bennett. "The business benefits are not just cost-related. The frustration levels are down, and people enjoy using the GUI computing approach. It's easy to learn, and doesn't require you to be a technocrat to obtain results."

\section{Corporate Data Network (CDN) SOE:}

In 1988, Telecom had trialed the use of fibre optic cable in the Melbourne CBD area. "That project interconnected LAN file servers in a few major buildings using either baseband or broadband backbones, and X.25 as the communications protocol over the Austpac network", said Bennett. "It formed the basis for CorpNet, Telecom's first wide area network." CorpNet was a bridged network and principally used by the Corporate and Government ${ }^{24}$ Business Unit. The network grew rapidly, and $2 \mathrm{mb} / \mathrm{sec}$ high speed links were established between Melbourne and other Australian capital cities. Other Business Units established networks along the same lines, and by the end of 1991, Telstra had thirteen large and autonomous WANs in operation. CorpNet was the largest of these networks.

"CorpNet was an early effort at LAN interconnect", said John Mitchell, Telstra's Manager for Network Rationalisation "and was partly used as a driver to progress to bigger and better things." CorpNet managed data traffic around Australia, but suffered from poor response times, was often unreliable, and was expensive to run. "Bridging was fine", said Mitchell "but we didn't want to be sending large files over Austpac. We also wanted something more scalable, so we started to architect a network that would sit alongside CorpNet and perform different functions."

Telstra's Information Technology Group (ITG) had been given the task of integrating the company's internal communications environment. ITG realised that significant benefits could be derived both in operational efficiency and reduction in telecommunications costs, by rationalising each of Telstra's many separate networks onto a common, Corporate Data Network (CDN) platform. Its vision was to implement a reliable, cost-effective, multi-protocol, high speed network that would be accessible to all of its business units, and capable of carrying high volume data traffic. The new network would allow connectivity from any LAN within Telstra to any corporate computing resource. Connectivity was seen as a necessary precondition for any move to integrated systems.

A network SOE was developed for the CDN based around IBM mainframes and an SNA architecture. The new network would be router-based rather than bridged, and would use a fibre distributed data interface $(\mathrm{FDDI})^{25}$ as its underlying transport medium. The CDN would initially comprise two elements:

$C D N(S)$ (via X.25 protocols) a public packet switched network service for low and medium volume traffic, based on Austpac

$C D N(B) \quad$ (via TCP/IP protocols) a broadband, non-switched, router-based backbone network used for high volume and time-critical data transfer

This choice of network services would enable application developers to choose the appropriate network service based on business needs, economic and performance criteria. It also satisfied OSA requirements (refer Figure 2) which specified that all computing equipment must be capable of connecting to the network. A short technical note on the two elements of Telstra's CDN is provided in Figure 4. 
Construction of CDN(B) commenced in July 1991, and underwent a phased implementation. CDN(B) has since expanded to become one of the largest, most effective and efficient enterprise-wide networks. Thousands of users access corporate computing resources and other LANs from more than 46,000 PCs and terminals, around 500 Unix workstations, and 1,200 servers (see also Figure 3).

\section{Figure 4: Telstra's Network SOE}

$\operatorname{CDN}(\mathbf{S}) \quad$ The switched element of the CDN is based on Austpac ${ }^{26}$ using X.25 protocols to provide a range of services to the client LAN environment. Services include terminal access to corporate systems, small file transfer capabilities, and file sharing on remote LANs. $\mathrm{CDN}(\mathrm{S})$ is reliable, low cost and flexible, has good response times, and is distance independent.

CDN(B) The $\operatorname{CDN}(B)$ is designed to meet Telstra's need for high volume, high-speed data communications, and large file transfer capabilities. LANs in each state are linked through high-speed router nodes that comprise a web of data links across Australia. The backbone extends to the two corporate data processing centres, proving high-bandwidth connection to Telstra's IBM mainframebased systems. Any workstation on a LAN connected to the backbone can access any other LAN on the network as well as any connected mainframe system. The backbone network supports a wide range of standards-based interfaces for different media, host connections and protocols. Network reliability on the CDN is ensured by diverse routing between cities. In 1994/95, sites were linked by high speed communications lines capable of supporting speeds from $2 \mathrm{mbps}$ to $34 \mathrm{mbps}$.

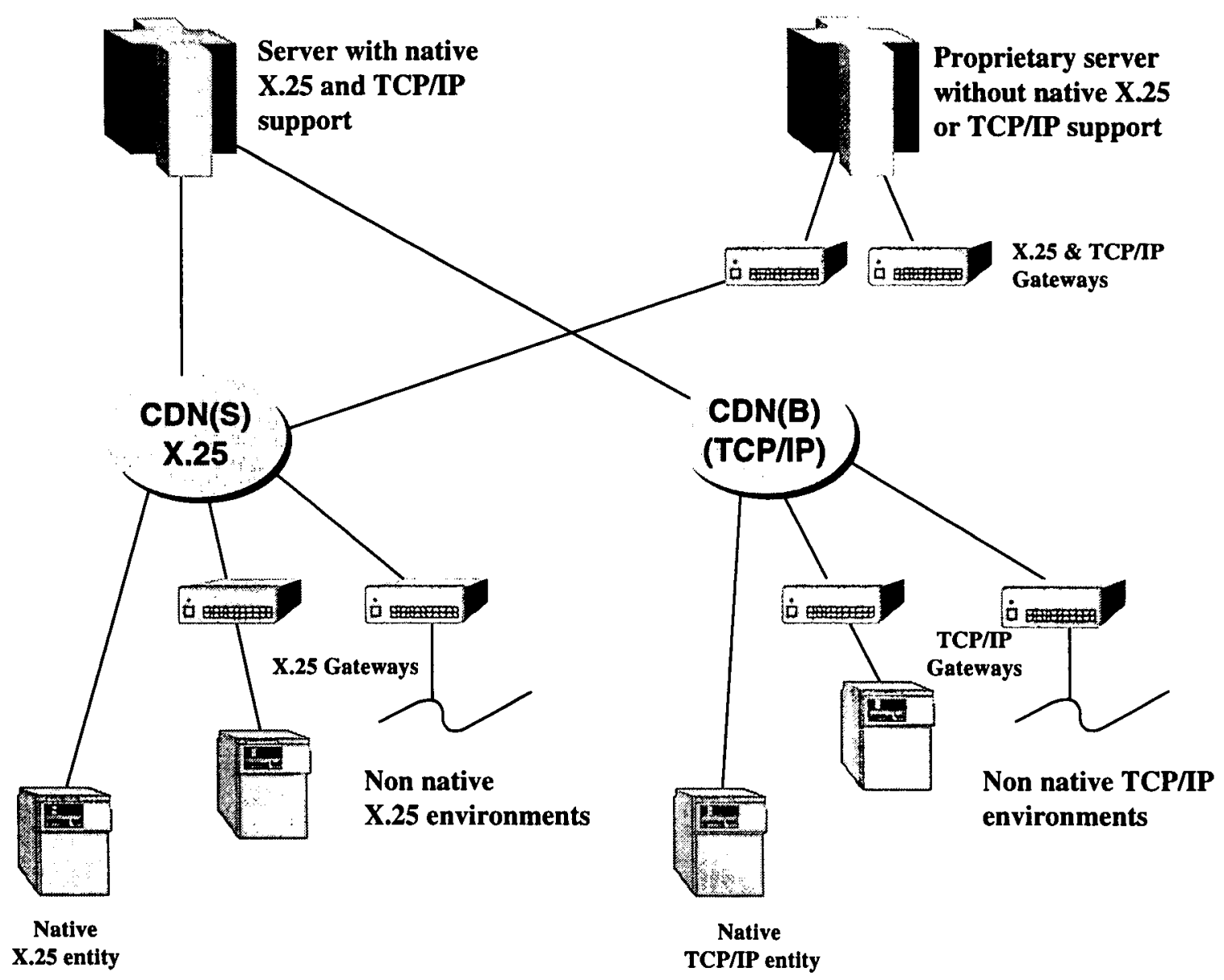


Telstra's CDN offers a fully end-to-end managed service, is highly scalable, and is designed to allow the company to grow the backbone network as internal traffic dictates (Telecommunications 1993). The network spans the Australian continent, and provides a wide range of applications essential to competitive customer service. Data carried by the CDN includes high volumes of electronic mail and transactional traffic, file transfer, and remote access to mainframe-based systems via Drift. Examples include core customer facing systems used primarily by the Commercial and Consumer division such as FLEXCAB (customer billing) and AXIS (service delivery), and internally focused systems such as FAMAD (financial accounting), RAPS (payroll), PERKINS (personnel), and FLEETMIS (fleet management).

The network also carries high bandwidth applications involving newer technologies such as imaging and video. In 1993, a gateway was established giving Telstra access to the global resources of the Internet. By mid-1994, the firm had a well developed site on the Internet's World Wide Web.

Telstra estimates the new network has saved the company approximately US $\$ 35$ million in annual running costs (Telecommunications 1993). In addition, the adoption of network standards has allowed the flexibility to interconnect best-of-breed technologies to all technical platforms as required. CDN(B) continues to grow and absorb existing non-standard and autonomous WANs. In 1996, the two separate elements of the CDN were merged into one fully integrated network.

\section{CONCLUSION}

The introduction of a standardised operating environment has provided Telstra for the first time with a consistent and effective, corporate-wide approach to IT. The SOE is still evolving. With more than 46,000 PCs and terminals in use, the introduction of computing standards has produced significant cost savings, and a major increase in Telstra's business effectiveness and skill levels. Benefits have included reduced training costs, greater buying power, simplified information sharing, and smoother network integration. "What we've ended up with," said Lovelock "is an amazing corporate asset. We have the most standard corporate desktop environment in the world in terms of user numbers, probably the third or fourth largest electronic mail network in the world, and a very, very large network taking over from the twenty or thirty competing wide area networks that had built up over the years."

Telstra views its technological infrastructure as strategically important and providing a foundation for the future growth of the company. "This story in many ways parallels the story of Telstra itself", mused James. "We've moved very quickly from being a state-based, somewhat insular organisation to being a nationally run firm. We need the infrastructure we have to continue to run the company the way we do. I can send email to anyone, anywhere in the company now, quickly, easily and reliably. I can sit at my $P C$ and watch our CEO deliver a speech from another location. With Drift, I can transparently view up to nine sessions simultaneously from different mainframes all on the one screen. Our previous infrastructure only allowed you to run the company the way it was wired."

Of necessity, Telstra's move to an Standard Operating Environment has involved a phased approach which has taken place over a six year period. The sheer size of the firm, and the complexity and diversity of its installed IT base, ensured that this project would never be rapid in its implementation. Telstra's positive experiences with the development and deployment of its desktop and network SOEs highlights some key issues for enhancing project success:

- the need for strong top management support to enable and sustain change of this magnitude. This was clearly provided by Telstra's CEO, Frank Blount.

- the project was driven by clearly defined, high level Key Business Imperatives. From the outset, the project was viewed as essential for the business, rather than just another IT project.

- the Key Business Imperatives in turn provided the foundation for the development of a detailed, Overall Systems Architecture (OSA) document, which specified how information technology would be deployed within Telstra to deliver maximum value to the business and the customer bottom line. This further strengthened linkages between the business and IT via integration with business processes.

- the OSA in turn provided the high level blueprint for specification and implementation of SOEs governing the desktop and network. Each SOE was carefully documented and circulated to all business units. In addition, all SOE developments were clearly communicated to Telstra staff.

- the need to provide compelling incentives in order to reduce resistance to change. Business units within Telstra were offered SOE-compliant software and hardware at little or no cost. Software and hardware purchased outside Desktop SOE specifications was not supported. 
The establishment of a standardised desktop has greatly reduced previous software and hardware incompatibilities, simplified acquisition arrangements, and significantly reduced purchase and training costs. The rationalisation of Telstra's many networks into a common, Corporate Data Network platform has substantially improved operational efficiencies, allowed simplified access to mainframebased applications via a single, consistent Windows-based interface, enabled the introduction of corporate-wide email thereby greatly improving communications within the firm, and greatly reduced telecommunication costs incurred by the firm. Driven by the firm's Key Business Imperatives and governed by the Overall Systems Architecture, Telstra's SOEs ensure that the firm has a flexible blueprint which is capable of changing according to business needs and/or ongoing technological advancements.

\section{REFERENCES}

ABM (1994). Australian Business Monthly, 14(12), October 1994. p.75.

AOTC (1992a).Australian and Overseas Telecommunications Corporation: Annual Report 1992. p.6.

AOTC (1992b). Australian and Overseas Telecommunications Corporation: Annual Report 1992. p.11.

S\&P (1993a). Standard \& Poor's Industry Profiles :Telecommunications, 23/06/93. p. 10. S\&P (1993b). Standard \& Poor's Industry Profiles: Telecommunications, 23/06/93. p. 19. Telecommunications (1993). Telecommunications, October 1993. p.89. 